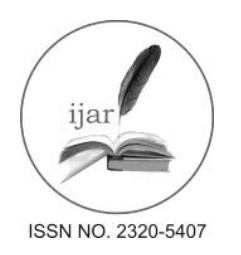

Journal homepage: http://www.journalijar.com

Journal DOI: $\underline{10.21474 / I J A R 01}$

RESEARCH ARTICLE

\title{
MICRO TEACHING AND ASSESSMENT OF PRACTICAL SKILLS IN PRECLINICAL STUDENT BY POSTGRADUATE STUDENTS.
}

Dr.L.Santhanalakshmi. M.D.DGO.MBA.

\section{Manuscript Info}

Manuscript History:

Received: 12 February 2016

Final Accepted: 25 March 2016

Published Online: April 2016

Key words:

*Corresponding Author

Dr.L.Santhanalakshmi.

\begin{abstract}
To implement ways to improve learning in small groups, interacting with them specifically in clinical and practical skill development and assessing them to improve the quality of learning and teaching. Post graduates play a key role in becoming a future Teacher.
\end{abstract}

Copy.Right, IJAR,2016. All rights reserved.

\section{Introduction:-}

Micro teaching a tool for training of student teachers originated in 1960 at Stanford University. Allen DW and Ryan K conceived this idea in terms of class size, number of students, scope of content and time. It provides a good opportunity to sample the level of Teaching, reflex practice in their skills I 'Ansen $\mathbf{J}$, to get feedback from peers and students within a short span of 5-7 minutes. It also enables them to reinforce learning, achieve perfection, shape their behaviour while sharing, listening, speaking in a group, acquiring leadership quality and team ethics when conducted in a safe, non threatening environment. Check list provided helps in lesson planning, discussion of the contents, closure of the sessions, validity, efficiency and acceptability Norman G R.

\section{Objective:-}

To enact, learn and reflect the process of small group learning in a preclinical small group learning set up.

Topic assigned was ' COLLECTION OF VENOUS SAMPLE' as an OSPE.

Group members involved were
a. Postgraduates in Physiology
b. 10 groups of students- 10 students in each group.
c. Professor as Facilitator.

Collection of Venous Blood Sampling demonstrated for 7 minutes by each Postgraduate.

Check list was also given to postgraduates.

1. Instruct the subject regarding blood collection.

2. Demonstrator to wear gloves.

3. Expose the vein.

4. Clean the skin over the area with spirit.

5. Allow the spirit to dry.

6. Choose a disposable syringe.

7. Fix the disposable needle on the syringe.

8. Put a tourniquet on the subject's arm.

9. Fix the vein with one hand. 
10. Place the needle with its tip at an angle below the vein.

11. Make the needle enter the vein.

12. The piston of the syringe is gradually withdrawn.

13. Loosen the tourniquet.

14. Collect the required amount of blood.

15. Take out the needle with the syringe.

16. Firmly press the insertion point with cotton swab.

17. Quickly transfer the collected Blood into a sterile container.

\section{Methods and Materials:-}

Study was done in Haematology Laboratory in Institute of Physiology, Madurai Medical College, Madurai. Sample consisted of 100 First MBBS student volunteers.

Method followed was as per The Tamilnadu Dr.M.G.R. Medical Universiy guidelines. Out of 40 marks allotted for practicals in Physiology, only 2 marks each were given for each skilled station.

Deficiencies pointed out by me were listed below;

1. Ideal group size is 6-8. Here 10 participants were there.

2. Punctuality.

3. Preparation- cotton swabs not kept in containers.

Dust bins not found.

Size of Disposable gloves not mentioned properly.

Demonstrator (postgraduates ) didn't notice a student bled a person not wearing a gloves.

Bleeder didn't allow spirit to dry.

Application of tourniquet was loose.

4. Content: Introduction of student staff relation not done.

Behaviour in the laboratory.

Involving all domains of learning.

\section{Conclusion:-}

Adopting simpler, non threatening, new model provides an opportunity to use their Teacher training tool on a wider scale. It also made the First M.B.B.S to be attentive in the class and understand the subject well by doing.

Postgraduates said it was a rewarding experience to act as a teacher and learner and there was a qualitative difference in Teaching and Learning.

Finally Small group teaching is an effective method of Teaching methodology. Simple language should be used for communication was stressed. It made active participation with purposeful activity by all students with no idle conversation. Post graduates are senior students anxious to help juniors in Learning skills.

\section{Questionairre:-}

Name

Year of Study

1. Duration of OSPE:

2. .Mark Distribution;

3. Atmosphere;

4. Able to understand the questionnaire; Yes / No.

5. Able to follow the language or medium of instruction; Yes / No.

6. Emotional aspect;

7. Orientation by students;

8. Settings to be modified ;

9. Necessity to memorise;

10. Learning Aptitude;

11. Feed back ;
Age in Years Sex

Medium of study at School ; Tamil / English

Adequate / Non Adequate / Any Suggession.

Accepted / Not Accepted / Any Suggession.

Threatening / Non Threatening.

Fearful / Not Fearful.

Good / Bad.

Yes / No.

Yes / No.

Too short / Too long / Sufficient.

Essential / Not Essential. 


\section{Observation:-}

1.Age distribution of participants; Males-Females. \%

$\begin{array}{llll}\text { Age group 18-19 years } & 20 & 68 & 88\end{array}$

$\begin{array}{llll}19-20 \text { years } & 07 & 05 & 12\end{array}$

$\mathrm{P}$ value $<0.001$. Significant.

\section{Duration of OSPE;}

Adequate $\quad 85 \%$

$\mathrm{P}$ value $<0.001$. Significant

Not adequate $15 \%$

3. Mark distribution compared to other Practicals

Agreed - $\quad 78 \%$

$\mathrm{P}$ value $<0.001$. Significant

Not Agreed- $\quad 22 \%$

\section{Mark Allotment;}

$P$ value $<0.001$. Significant

\section{Understanding the questionnaire;}

$P$ value $<0.001$. Significant

\section{Feedback; Good / very Good.}

$\mathrm{P}$ value $<0.001$. Significant
Sufficient - $\mathbf{7 8 \%}$

Not Sufficient- $22 \%$

Yes - $\quad 87 \%$

$$
\text { No - } 13 \%
$$

Good-96\%

Very Good-04\%.

Test - Chi Square Test used for consolidated data.

Software SPSS 16 Sigma stat.

Results were statistically analysed using Chi Square Test. Based on the feedback, students suggested that time management for all practicals except for OSPE (Objective Structured Pattern Examination) may be increased by one more minute, so that they can complete and score full marks.

\section{Bibliography;}

1. Allen DW, Ryan K. Micro Teaching. Reading, Massachusettes. Addison -Wesley;1969.

2. I' Anson J, Rodrigues S, Wilson G, Mirrors, reflections and refractions.Contribution of microteaching to reflective practice.Eur.J Teach Educ;2003.26;189-99.

3. Merglers AG, Tangena D .Using microteaching to enhance teacher efficacy preservative teachers. Teaching Educ. 2010;21;199-210.

4. Microteaching revisited; Tejender Singh. The National Medical Journal Of India. Vol.24, No. 6, 2011.Page no.292. 